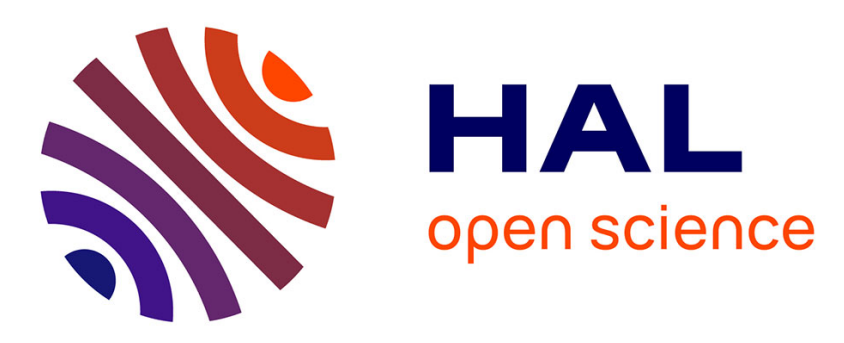

\title{
Excellent Semiconductors Based on Tetracenotetracene and Pentacenopentacene: From Stable Closed-Shell to Singlet Open-Shell
}

Tanguy Jousselin-Oba, Masashi Mamada, Jérôme Marrot, Antoine Maignan, Chihaya Adachi, Abderrahim Yassar, Michel Frigoli

\section{To cite this version:}

Tanguy Jousselin-Oba, Masashi Mamada, Jérôme Marrot, Antoine Maignan, Chihaya Adachi, et al.. Excellent Semiconductors Based on Tetracenotetracene and Pentacenopentacene: From Stable ClosedShell to Singlet Open-Shell. Journal of the American Chemical Society, 2019, 141 (23), pp.9373-9381. 10.1021/jacs.9b03488 . hal-02347038

\section{HAL Id: hal-02347038 \\ https://hal.science/hal-02347038}

Submitted on 5 Nov 2019

HAL is a multi-disciplinary open access archive for the deposit and dissemination of scientific research documents, whether they are published or not. The documents may come from teaching and research institutions in France or abroad, or from public or private research centers.
L'archive ouverte pluridisciplinaire HAL, est destinée au dépôt et à la diffusion de documents scientifiques de niveau recherche, publiés ou non, émanant des établissements d'enseignement et de recherche français ou étrangers, des laboratoires publics ou privés. 


\section{Excellent Semiconductors Based on Tetraceno- Tetracene and PentacenoPentacene: From Stable Closed-Shell to Singlet Open-Shell.}

Tanguy Jousselin-Oba, ${ }^{\dagger}$ Masashi Mamada, ${ }^{*}{ }^{\ddagger}$ Jérôme Marrot $^{\dagger}$ Antoine Maignan, ${ }^{\S}$ Chihaya Adachi, ${ }^{\ddagger}$, Abderrahim Yassar, ${ }^{\#}$ Michel Frigoli* ${ }^{\dagger}$

$\dagger$ UMR CNRS 8180, UVSQ, Institut Lavoisier de Versailles, Université Paris-Saclay, 45 avenue des Etats-Unis, 78035 Versailles Cedex, France.

\$ Center for Organic Photonics and Electronics Research (OPERA), JST ERATO Adachi Molecular Exciton Engineering Project, and Education Center for Global Leaders in Molecular System for Devices, Kyushu University, Kyushu University, Nishi, Fukuoka, 819-0395 Japan.

\| International Institute for Carbon Neutral Energy Research (WPI-I2CNER), Kyushu University, Nishi, Fukuoka 819-0395, Japan

§ UMR CNRS 6508, Normandie Université, CRISMAT, ENSICAEN, UNICAEN, F-14000 Caen, France.

\# UMR CNRS 7647, LPICM-École Polytechnique, 91128 Palaiseau Cedex, France.

Supporting Information Placeholder

\begin{abstract}
Designing stable open-shell organic materials through the modifications of the $\pi$-topology of molecular organic semiconductors have attracted recently considerable attention. However, their uses as an active layer in organic field-effect transistors (OFETs) are very limited and the obtained hole and electron charge mobilities are around $10^{-3} \mathrm{~cm}^{2} \mathrm{~V}^{-1} \mathrm{~s}^{-1}$. Herein, we disclosed the synthesis of two materials so-called tetracenotetracene (TT) and pentacenopentacene (PP) which have low band gap of 1.79 and $1.42 \mathrm{eV}$, respectively. Their ground state natures have been investigated by different experiments including steady state absorption, electron spin resonance, superconducting quantum interfering device (SQUID) and variable temperature NMR along with DFT calculations. TT and PP have closed-shell and singlet open-shell structures in their ground state, respectively, and possess high stability. Their biradical characteristics were found to be 0.50 and 0.64 . The origin of the open-shell character of $\mathbf{P P}$ is related to the concomitant opening of two tetracenes with the recovering of two extra aromatic sextets and a small HOMOLUMO energy gap (gap $<1.5 \mathrm{eV}$ ). Thanks to the high stability, thin film OFET devices could be fabricated. In TG-BC configuration PP shows remarkably high hole mobility of $1.4 \mathrm{~cm}^{2} \mathrm{~V}^{-1} \mathrm{~s}^{-1}$ while TT exhibits a hole mobility of $0.77 \mathrm{~cm}^{2} \mathrm{~V}^{-1} \mathrm{~s}^{-1}$. In configuration of BG-TC, ambipolar behaviors for both were obtained with hole and electron mobilities of 0.21 and $0.01 \mathrm{~cm}^{2} \mathrm{~V}^{-1} \mathrm{~s}^{-1}$ for $\mathbf{P P}$ and 0.14 and $0.006 \mathrm{~cm}^{2} \mathrm{~V}^{-1} \mathrm{~s}^{-1}$ for TT.
\end{abstract}

\section{INTRODUCTION}

Acenes composed of laterally condensed benzenoid rings are a special class of polycyclic aromatic hydrocarbons (PAHs) that have been intensively studied in the last two decades. ${ }^{1}$ Functionalized acenes up to five benzene rings have been of interest in potential applications going from organic light-emitting diodes (OLEDs), organic photovoltaic devices to organic field-effect transistors (OFETs). ${ }^{2}$ For this latter application, the benchmark of soluble acenes is 6,13-bis(triisopropylsilylethynyl)pentacene (TIPS-PEN) that showed excellent compatibility between stabil
Chart 1. Clar's structures of the closed-shell form of TIPSAnthanthrene, TT and PP.

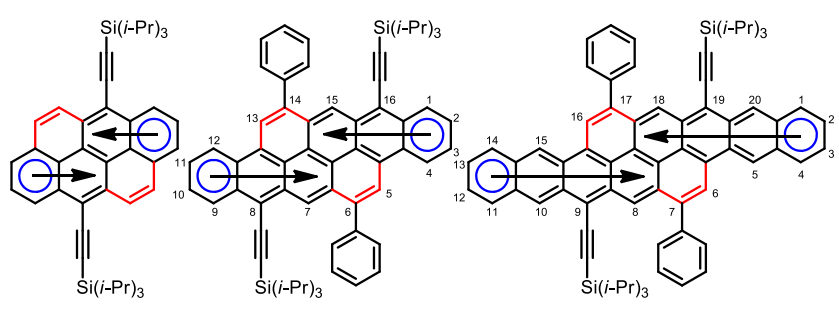

ANT

TT

PP

ity and solubility and exhibited good charge transport. ${ }^{3}$ Since the mobilities in OFETs depends on the packing in the solid phase and the reorganization energy that decreases with the acene length, longer acenes containing more than five rings were particularly promising for optoelectronic devices. ${ }^{4}$ Although in the past decade, the synthesis of soluble hexacene, heptacene and nonacenes functionalized with silyl acetylenes was achieved, their stabilities in solution were detrimental to show their intrinsic properties. ${ }^{5}$ Indeed, nowadays, it is clear that longer acenes should be regarded as singlet open-shell PAHs in the ground state. ${ }^{6}$ In recent years, a large number of delocalized biradical PAHs that can be written with a Kekulé structure including bisphenalenyls, zethrenes, indenoacenes, anthenes, peri-tetracene and rylene ribbons have been disclosed. ${ }^{7-13}$ Compared to longer acenes, the stability of those biradicals are genuinely higher due to the presence of at least two aromatic sextets. For most biradical PAHs, the reactive sites are functionalized with bulky groups which are not really excellent groups to promote good $\pi$-stacking in the solid state, leading to charge mobilities of around $10^{-3} \mathrm{~cm}^{2} \mathrm{~V}^{-1} \mathrm{~s}^{-1}$ at best in OFETs. ${ }^{8 e, 10 e, 10 \mathrm{~h}}$ Finding a chemical structure combining a biradical character in the ground state, high stability and suitably functionalized to promote high $\pi$-overlap in the solid state is highly appealing for the fabrication of ambipolar OFET devices.

In the recent years, some groups including us have been interested on two dimensional (2D) PAHs based on tetracenotetracene derivatives (TT) that correspond to two tetracenes fused at the 
zigzag edge in different manners. ${ }^{14}$ They have shown similar optoelectronic properties like TIPS-PEN associated with high charge mobility and stability. The enhanced stability has been associated to the presence of two aromatic sextets in the molecule, leading to high distortion energy in interaction with oxygen. ${ }^{15}$ Indeed, the change of aromaticity from TT to its oxidized form is globally comparable to that observed from anthracene to its oxidized form. ${ }^{16}$ Since TT can be regarded as a dibenzoanthanthrene and TT functionalized with only TIPS-acetylene groups in the 8,16 positions has an absorption maximum $\left(\lambda_{\max }\right)$ at $648 \mathrm{~nm}$, corresponding to a bathochromic shift of $153 \mathrm{~nm}(0.59 \mathrm{eV})$ in comparison with TIPS-anthranthrene ANT (495 nm), ${ }^{14 \mathrm{~d},}{ }^{17}$ the corresponding TIPS-dinaphto-anthranthrene so called pentacenopentacene $\mathbf{P P}$ as shown in Chart 1 should have a $\lambda_{\max }$ around 800 $\mathrm{nm}$, absorption behavior in between alkylsilylhexacene $(740 \mathrm{~nm})$ and alkylsilylheptacene $(840 \mathrm{~nm}) .^{5 a}$ Since longer acenes are singlet open-shell in the ground state and PP is an acene-like molecule, if the energy gap HOMO-LUMO is a critical factor for the occurrence of the biradical character as shown recently by $\mathrm{Wu}$, et $a l$. on their study of rylene ribbons, $\mathbf{P P}$ should be a singlet biradical and could be an excellent organic semiconductor. ${ }^{13}$

Herein, we report an efficient synthesis of $\mathbf{P P}$ and its smaller homologue TT for comparison and discuss their optoelectronic properties and stabilities and their ground-state electronic structures studied by different experiments and density functional theory (DFT) calculations and finally theirs charge transport behaviors in OFETs.

Pristine PP has been recently prepared using a simple methodology so-called dehydrative $\pi$-extension (DPEX) from the cyclisation of pyrene functionalized with two 2-naphthaldehyde derivatives. ${ }^{18}$ However due to the insolubility of the material, no optoelectronic properties have been reported.

TT and PP have been functionalized with TIPS-acetylene in the most reactive positions as recently shown in $\mathbf{T T}$ derivatives, to ensure stability and solubility and to promote good $\pi$-stacking in solid state. ${ }^{14 \mathrm{~b}}$ The phenyl groups are here not only to avoid the competition between 1,4- and 1,2-addition on the carbonyl groups of the TIPS-acetylene groups at the last stage of the preparation but also to be eventually beneficial for the solubility and the packing issues. ${ }^{14 \mathrm{c}-\mathrm{d}}$

\section{RESULTS AND DISCUSSION}

The synthetic path for the preparation of TT and PP derivatives is depicted in Scheme 1 and follows the strategy used previously for the synthesis of TT derivatives. ${ }^{14 \mathrm{~b}}$ From 1,6-dibromo-3,8diphenylpyrene $\mathbf{1}$, cross-coupling reaction with phenyl- or naphtylboronic acid pinacol ester derivatives afforded diester $\mathbf{2}$ and $\mathbf{3}$ respectively in yield above 90\%. The TT-dione 4 and the PPdione 5 were obtained in excellent yield via a double intramolecular acylations using TfOH as activator. ${ }^{18}$ Addition of the lithium (triisopropylsilyl)acetylide to either $\mathbf{4}$ and $\mathbf{5}$ followed by $\mathrm{SnCl}_{2}$ mediated reduction of the diol intermediates afforded the desired TT as dark blue solid and PP as dark green solid with yield around $50 \%$. The structure of TT was confirmed by X-ray diffraction and the purity of samples was checked by ${ }^{1} \mathrm{H}$ NMR, MALDITOF measurement in which only one peak assigned to molecular ion of the materials was observed and by elemental analysis for PP (see Supporting information). For this latter analysis, the expected values for carbon and hydrogen are $87.40 \%$ and $6.93 \%$ and the found values are $87.16 \%$ and $6.96 \%$.

Optical and Electrochemical properties: TT and PP are blue and light green in chloroform solution, respectively. The UV/Vis absorption spectrum of TT shows typical acene-like vibronic feature with three distinct bands at 559, 608, and $662 \mathrm{~nm}\left(\lambda_{\max }\right)$ that increase in intensity going towards the low energy of the

Scheme 1. Synthetic path of TT and PP.

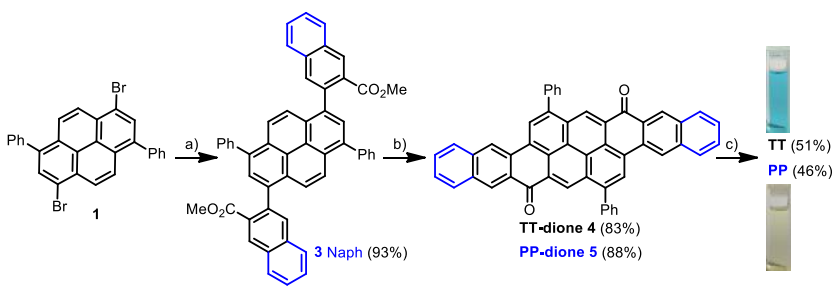

(a) Ester boronic derivatives, $\mathrm{Pd}_{2}(\mathrm{dba})_{3}$, S-Phos, $\mathrm{K}_{3} \mathrm{PO}_{4}$, toluene/water, $100^{\circ} \mathrm{C}$; (b) $\mathrm{TfOH}, 1,2$-dichloroethane, $90^{\circ} \mathrm{C}$; (c) 1$)$ Lithium TIPS-acetylide, THF, $0^{\circ} \mathrm{C}, 2$ ) $\mathrm{SnCl}_{2} / \mathrm{HCl}$ for $\mathbf{T T}$ and $\mathrm{SnCl}_{2}$, toluene, r.t. for $\mathbf{P P}$

spectrum (Figure 1 (a)). In the similar manner, the typical three bands are observed for PP with $\lambda_{\max }$ found at $806 \mathrm{~nm}$ which is red-shifted of $142 \mathrm{~nm}(0.33 \mathrm{eV})$ compared to that of TT and $\lambda_{\max }$ appears between hexacene $(740 \mathrm{~nm})$ and heptacene $(840 \mathrm{~nm})$ functionalized with silyl-acetylene groups as expected. ${ }^{5 a}$ Like functionalized heptacene derivatives and most of singlet biradicals, after $\lambda_{\max }$, a weak and broad transition is observed that extends up to $900 \mathrm{~nm}^{5 \mathrm{~b}-\mathrm{c}}$ This small transition that could be attributed to the HOMO, HOMO $\rightarrow$ LUMO, LUMO double excitation, is the signature that $\mathbf{P P}$ has a significant contribution of the singlet biradical form in the ground state. ${ }^{20,7 a}$ It is noteworthy that the molar absorption coefficient $(\varepsilon)$ at $\lambda_{\max }$ of TT $\left(94000 \mathrm{~L} \mathrm{~mol}^{-1} \mathrm{~cm}\right.$ $\left.{ }^{1}\right)$ is 1.27 larger than the value obtained for PP $\left(74000 \mathrm{~mol}^{-1} \mathrm{~cm}\right.$ ${ }^{1}$ ), indicating that TT has a higher over whole aromaticity than PP. Indeed, in a similar manner, TIPS-tetracene $\left(32000 \mathrm{~L} \mathrm{~mol}^{-1}\right.$ $\left.\mathrm{cm}^{-1}\right)$ has an $\varepsilon$ value 1.23 higher than TIPS-PEN $\left(26000 \mathrm{~L} \mathrm{~mol}^{-1}\right.$ $\left.\mathrm{cm}^{-1}\right) .^{21}$

(a)

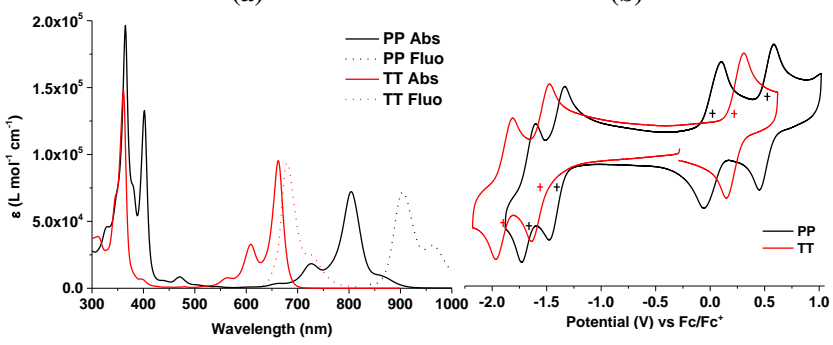

Figure 1. (a) Absorption and emission spectra in chloroform and (b) Cyclic voltammetry of TT and PP in chlorobenzene.

TT exhibits significant fluorescence properties in chloroform solution and emits at $679 \mathrm{~nm}$ with the fluorescence quantum yield of $63 \%$ and the total decay lifetime of $7.6 \mathrm{~ns}$. As for low band gap materials with a significant contribution of the singlet biradical form in the ground state, PP shows very weak fluorescence at 904 $\mathrm{nm}$ when excited at $806 \mathrm{~nm}$, with the fluorescence quantum yield of $0.8 \%$ and the total decay life time of $4.3 \mathrm{~ns}$. It is noteworthy that the fluorescence spectrum obtained using an excitation wavelength of $365 \mathrm{~nm}$, on top of the band at $904 \mathrm{~nm}$, exhibits two weak fluorescence bands at $460 \mathrm{~nm}$ and $670 \mathrm{~nm}$ that increase strongly in intensity with the number of scans (see Supporting Information). These results indicate that $\mathbf{P P}$ degrades readily to two different oxidation products upon high energy irradiation.

Electrochemistry: Cyclic voltammetry (CV) was performed to investigate the electrochemical behaviors and probe the HOMO/LUMO energy levels of materials. The measurements were performed in chlorobenzene and half-wave potentials were determined relative to $\mathrm{Fc} / \mathrm{Fc}^{+}$. CVs of materials are shown in Figure 1 (b). Both TT and PP show amphoteric redox behaviors and exhibit two reversible reductions and two reversible oxidations for PP and only one reversible oxidation for TT. Half-wave 
potentials of the first oxidation/reduction peaks were at $0.23 /-1.56$ for TT and $0.02 /-1.40 \mathrm{~V}$ for PP. From these values, the HOMO/LUMO energy levels were found to be $-5.03 /-3.24$ $\mathrm{eV}$ for TT and $-4.82 /-3.40 \mathrm{eV}$ for PP. Thus, the electrochemical energy gaps were estimated to be 1.79 and $1.42 \mathrm{eV}$, respectively. As expected increasing the number of benzenoid rings in linear fashion reduces the HOMO-LUMO band gap by stabilizing the LUMO and destabilizing the HOMO energy levels at the same time. The ionization potential for the thin-film of PP determined using a photoelectron yield spectroscopy was $-4.87 \mathrm{eV}$, which is in good agreement with the HOMO level measured by CV (See Supporting Information).

Stability experiments of the materials in saturated airchloroform solution in lightening laboratory were performed and compared to TIPS-PEN by monitoring the change of UV/Vis absorption over time (Figure 2, see Supporting Information). TT has a half-life of 6.5 days and it is about 3.8 times more stable than TIPS-PEN (1.7 days). As TT and TIPS-PEN have absorption bands in the same region of the spectrum and the $\varepsilon$ value of TT is about 3.6 higher than that of TIPS-PEN, TT is intrinsically 14 times more stable than the TIPS-PEN. Remarkably, PP is about 3 times more stable than TIPS-PEN with a half-life of 4.9 days that increases to 19 days in presence of air without light. In solid state, $\mathbf{P P}$ is absolutely stable.

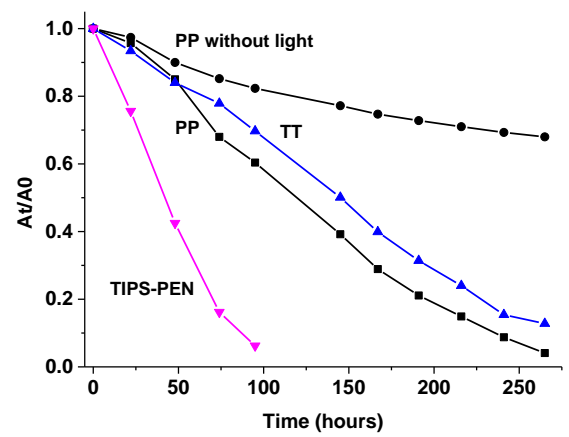

Figure 2. Change of UV/Vis absorption (followed at their own $\left.\lambda_{\max }\right)$ over time in chloroform $(20 \mu \mathrm{m})$ of $\mathbf{T T}$ and $\mathbf{P P}$ compared to TIPS-PEN.

VT ${ }^{1} H$ NMR, ESR and SQUID measurements: Since the UV/Vis spectrum of PP shows that the singlet biradical state contributes in the ground state, variable temperature (VT) ${ }^{1} \mathrm{H}$ NMR spectra were performed in 1,2-dichlorobenzene- $\mathrm{d}_{4}$ from 0 to $140{ }^{\circ} \mathrm{C}$ (only shown up to $80{ }^{\circ} \mathrm{C}$, Figure 3 (a), see Supporting Information).

The assignments of the ${ }^{1} \mathrm{H}$ NMR signals were based on COSY and NOESY experiments recorded at $20^{\circ} \mathrm{C}$ (see Supporting Information). The two singlet signals at $9.72 \mathrm{ppm}$ and $9.67 \mathrm{ppm}$ were assigned to protons $\mathrm{H} 8, \mathrm{H} 18$ and $\mathrm{H} 10, \mathrm{H} 20$ respectively based on the presence of dipolar contacts with protons of the TIPS groups and a weak dipolar contact with protons of the phenyl groups for $\mathrm{H} 8$ and $\mathrm{H} 18$. The two other singlet signals at $9.53 \mathrm{ppm}$ and $9.21 \mathrm{ppm}$ were assigned to $\mathrm{H} 5, \mathrm{H} 15$ and $\mathrm{H} 6, \mathrm{H} 16$ respectively. Even though protons H6, H16 are in close proximity with protons of the phenyl groups, no dipolar contact was observed. Therefore, we assume that the most deshielded signal should be assigned to protons $\mathrm{H} 5, \mathrm{H} 15$ since they are located at the zigzag edge of a ring which is delocalized in nature and the most shielded one assigned to protons H6, H16 since they are located at the side of the molecule. The protons of the phenyl groups were easily identified at 8.09, 7.76 and $7.67 \mathrm{ppm}$ for the protons in ortho, meta and para of the substitution respectively. The most deshielded signal centered at $7.51 \mathrm{ppm}$ was attributed to protons $\mathrm{H} 2, \mathrm{H} 12$ and $\mathrm{H} 3, \mathrm{H} 13$ since they are at the side of the molecule.
Theirs neighbors protons $\mathrm{H} 1, \mathrm{H} 11$ and $\mathrm{H} 4, \mathrm{H} 14$ were found to be at $8.18 \mathrm{ppm}$ and $8.15 \mathrm{ppm}$ respectively based on COSY and the presence of a dipolar contact between $\mathrm{H} 1, \mathrm{H} 11$ and the protons of the TIPS.

The VTR experiments show that at $0{ }^{\circ} \mathrm{C}$, all the signals are sharp and as the temperature increases, the signals of protons $\mathrm{H} 8$, $\mathrm{H} 18$ and $\mathrm{H} 10, \mathrm{H} 20$ and H1, H11 broaden and disappear completely at $80{ }^{\circ} \mathrm{C}$. The signals of protons $\mathrm{H} 5, \mathrm{H} 15$ and $\mathrm{H} 2, \mathrm{H} 12$ and $\mathrm{H} 3$, $\mathrm{H} 13$ broaden but do not collapse even at $140{ }^{\circ} \mathrm{C}$ (see Supporting Information). The signal of protons $\mathrm{H} 6, \mathrm{H} 16$ and the three signals related to the protons of the phenyl groups are not much altered. All the signals are recovered when the sample is cooled back to r.t indicating that PP is stable when heated in solution. The ${ }^{1} \mathrm{H}$ NMR signal broadening by increasing temperature is a typical phenomenon for singlet open-shell PAHs and results from a thermally accessible triplet biradical form which is slightly higher in energy than the singlet biradical one. Hence, the spin distribution of the triplet biradical of PP (Figure 3 (b)) was calculated and indicates that the spin density is highly localized at the zigzag edge. The protons that hold the highest spin density collapse in VT ${ }^{1} \mathrm{H}$ NMR experiment whereas the other protons with less spin density or with no density at all broaden or are not much altered.

(a)
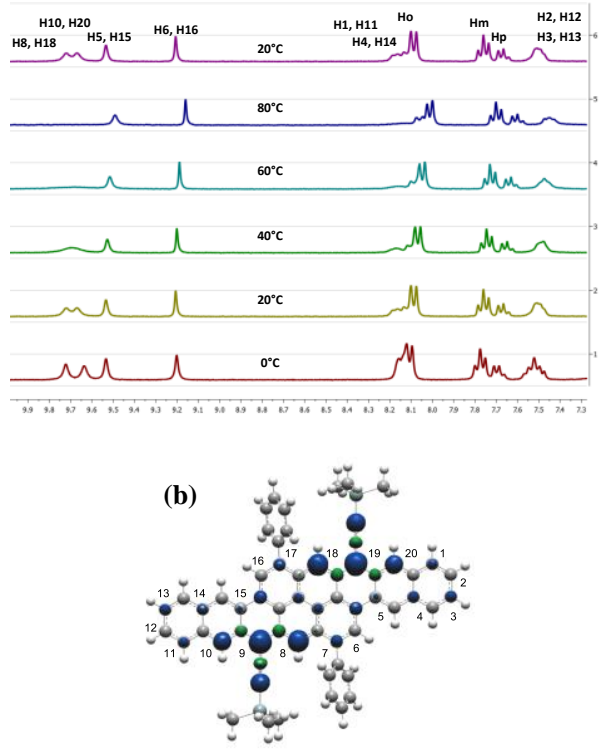

(c)

(d)

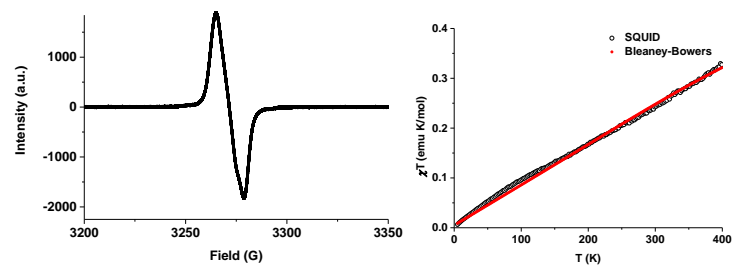

Figure 3. (a) VT ${ }^{1} \mathrm{H}$ NMR spectra (aromatic region) of $\mathbf{P P}$ in $o$ DCB- $\mathrm{d}_{4}$. The signal assignments referred to the structure shown in Chart 1; (b) Spin density of the triplet biradical of PP; (c) ESR spectrum of $\mathbf{P P}$ in powder at r.t.; (d) $\chi_{m} T$ versus $\mathrm{T}$ plot for $\mathbf{P P}$ in the solid state in the temperature range $5-400 \mathrm{~K}$ from SQUID measurements.

In solid state, $\mathbf{P P}$ exhibits a ESR signal at $\mathrm{g}=2.0026$ at room temperature (Figure 3 (c)) which is typical for singlet open-shells with triplet state thermally accessible. The super conducting quantum interference device (SQUID) measurement at the temperature range of $5-400 \mathrm{~K}$ shows that the magnetic succeptibility $\left(\chi_{m} T\right)$ decreases with a reduction of temperature (Figure 3 (d)). Fitting the data by using Bleaney-Bowers equation gave a singlet-triplet energy gap $\left(\Delta E_{\mathrm{S}-\mathrm{T}}\right)$ of $-4.85 \mathrm{kcal} / \mathrm{mol}(2 J=-$ 
$\left.1696 \mathrm{~cm}^{-1}\right) .{ }^{23,24}$ Similar $\chi_{m} T$ versus $\mathrm{T}$ plots and $\Delta E_{\mathrm{S}-\mathrm{T}}$ values were obtained recently with biradical picene derivatives. ${ }^{10 \mathrm{~h}}$

Theoritical Calculations: In order to have a deeper insight into the electronic nature of PP, density functional theory (DFT) analysis was performed using Gaussian 16 except for anisotropy of the current induced density (ACID) plot and nucleusindependent chemical shift (NICS) calculations (see Supporting Information for details). ${ }^{25,26}$ The biradical character was estimated from the electron occupancies of the frontier natural orbitals through the Yamaguchi's scheme $\left(y_{0}\right)$ at UHF/6-31G(d,p) level of theory. ${ }^{27}$ For comparison, the biradical character of PEN, hexacene (HEX) and heptacene (HEPT) and their homologues functionnalised with TIPS-acetylene were also calculated (Table 1, see Supporting information). For the calculation, the TIPS groups were replaced by TMS groups. For all systems under studies, the TMS-acetylene groups increase the biradical character by about $0.04-0.06$ due to the extra resonance afforded by each spin and reduces the energie difference between singlet and triplet open-shell forms. The calculations predict that pristine TT and PEN and theirs functionnalized homologues have a closed-shell ground state whereas PP and higher acenes have an open-shell ground state. PP has a biradical character $y_{0}$ of $64 \%$, value in between of TMS-HEX (58\%) and TMS-HEPT (68\%). Indeed, the biradical character increases while the band gap and the singlet-triplet energy gap decrease.

Table 1. DFT calculation of the biradical character $\left(y_{0}\right)$

\begin{tabular}{ccccc}
\hline Compound & $\mathbf{y}_{\mathbf{0}}{ }^{\mathbf{a}}$ & $\Delta E(\mathbf{O S}-\mathbf{C S})^{b}$ & $\Delta E_{\mathbf{S - T}}{ }^{b}$ & $\left\langle\mathbf{s}^{2}\right\rangle^{b}$ \\
\hline native TT & 0.45 & 0 & -17.19 & 0 \\
TT & 0.50 & 0 & -13.86 & 0 \\
native PP & 0.60 & -0.109 & -8.43 & 0.265 \\
PP & 0.64 & -0.374 & -6.54 & 0.460 \\
PEN & 0.41 & 0 & -18.00 & 0 \\
TMS-PEN & 0.47 & 0 & -13.55 & 0 \\
TMS-HEX & 0.58 & -0.256 & -8.40 & 0.373 \\
TMS-HEPT & 0.68 & -1.898 & -5.46 & 0.828 \\
TMS-DNP & 0.57 & 0 & -9.50 & 0 \\
${ }^{a}$ at UHF/6-31G(d,p) level of theory; ${ }^{b}$ at B3LYP/6-311G(d,p) level \\
\hline \multicolumn{5}{c}{}
\end{tabular}

The calculated singly occupied molecular orbital (SOMO) profiles of the $\alpha$ and $\beta$ spins of the singlet biradical form of PP, shown in Figure 4 (a) are highly delocalized and the spin density map indicates that the largest spin densities are typically found at the zigzag edge (Figure 4 (b)). The couple of carbons C9 and C19 $(0.188)$ holds the largest spin density, followed by the carbons C8 and C18 (0.158), and then by the carbons C10 and C20 (0.104). The carbons C9 and C19 are protected with TIPS-acetylene and the latter bears appreciable spin density (0.099) and so takes part to the delocalization of the spin as mentioned above. These results indicate that PP should be considered as a resonance hybrid structure between the closed-shell form and six open shell resonance forms having the highest thermodynamic stabilities by keeping four aromatic sextets as shown in Figure 4 (c).

The origin of the open-shell nature of PP is interesting. As shown in Chart 1, the Clar's structures of ANT, TT and PP possess two aromatic sextets that are delocalized over two, three and four rings respectively. These representations correspond to three Clar's resonance forms for ANT, to eight Clar's resonance forms out of ten possible for TT and to fifteen out of nineteen possible for PP (see Supporting information). In contrast to ANT that cannot hold an aromatic sextet in the rings marked in red according to Clar's sextet rule, the missing two structures for TT and four for PP correspond to those where one aromatic sextet would be localized on that rings that can be neglected (2/10 for TT and 4/19 for PP) (See Supporting Information). ${ }^{28}$

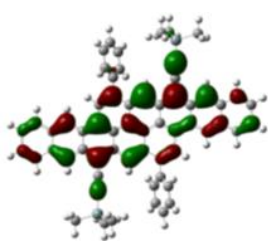

SOMO- $\alpha$

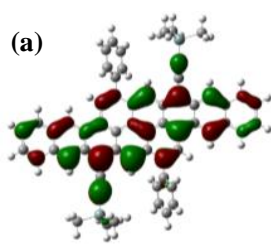

SOMO- $\beta$ (b)

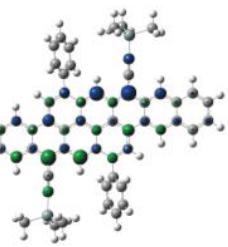

Spin distribution

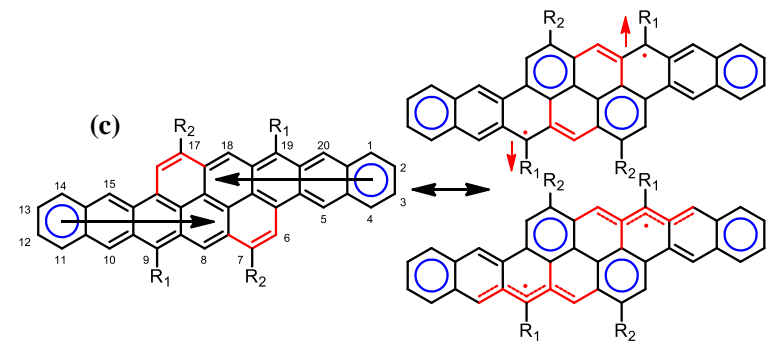

Figure 4. (a) Calculated SOMOs for the $\alpha$ and $\beta$ electrons (UCAM-B3LYP) and (b) spin density distribution of the singlet biradical of PP with TMS group for simplification; (c) Resonance between the closed-shell and the open-shell forms of PP.

These representations would suggest that the rings marked in red should have a bond with a high degree of double character (shortest bond length) and the remaining bonds at the zigzag edge should be similar to naphthalene for ANT, anthracene for TT and tetracene for $\mathbf{P P}$.

The theoretical bond lengths of ANT, TT and PP along with those of naphthalene, anthracene and tetracene are depicted in Figure 5. The bond lengths at the zigzag edge of the acenes show bond length alternation and the double character of bond $\mathbf{a}$ increases with the acene length going from $1.373 \AA$ for naphthalene to $1.367 \AA$ for anthracene and $1.363 \AA$ for tetracene. For the perifused systems, as expected the bond lengths of bonds a are the shortest ranging from $1.355 \AA$ for ANT to $1.358 \AA$ for PP indicating their high degree of double bond character. The remaining bond lengths of ANT, TT and PP at the zigzag edge are very similar to naphthalene, anthracene and tetracene respectively except for the bonds $\mathbf{c}$ and $\mathbf{d}$. Since these bonds are very similar for the three peri-fused systems, we can assume that these bonds lengths are governed to some extend by the geometry of the molecules.

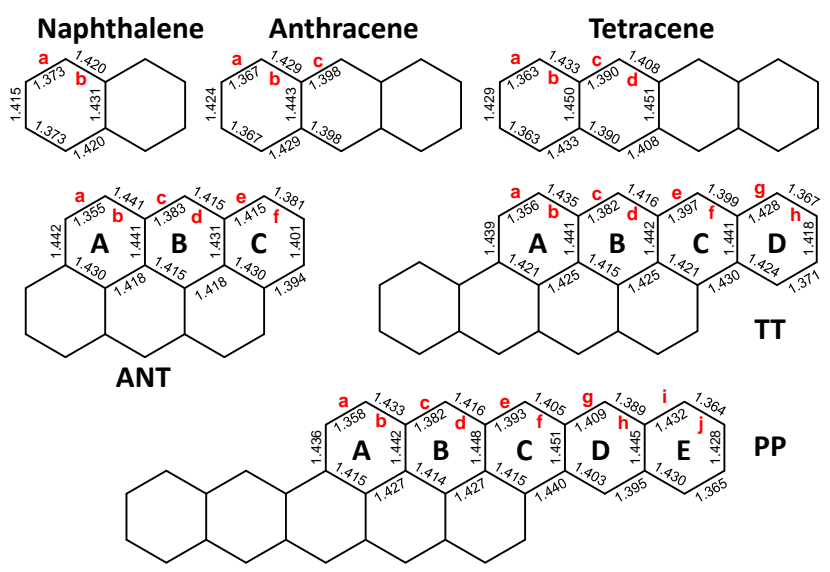

Figure 5. Theoretical bond lengths of naphthalene, anthracene, tetracene, pristine ANT, TT and PP.

The Clar's representations of the three peri-fused systems are also in agreement with the calculation of NICS using the NICS- 
XY scan and $\pi$-only methods and the corresponding anisotropy of the current induced density (ACID) plot (Figure 6). ${ }^{25-26}$

For all systems, rings A sustain the lowest diatropic ring current with NICS(1.7) $\pi z z$ values ranging from -10.0 to $-10.4 \mathrm{ppm}$ indicating that rings $\mathrm{A}$ are not delocalized rings. The NICS(1.7) $)_{z z}$ values of rings $\mathrm{B}$ and $\mathrm{C}$ for $\mathrm{ANT}$, rings $\mathrm{B}, \mathrm{C}$ and $\mathrm{D}$ for TT and rings $\mathrm{B}, \mathrm{C}, \mathrm{D}$ and $\mathrm{E}$ for $\mathbf{P P}$ are similar to those obtained for naphthalene, anthracene and tetracene respectively (see Supporting Information). The acid plots indicate that the diatropic ring current is mainly delocalized at the zigzag edge and all the rings sustain a diatropic ring current (red arrows) like for delocalized rings except for rings $\mathrm{A}$ for which the diatropic ring current (blue arrows) is rather related to a conjugation. There is also a transannular ring current (black arrow) below rings A due to the fact that the rings below are delocalized rings in nature confirming the Clar's representation of the three peri-fused systems as shown in Chart 1.

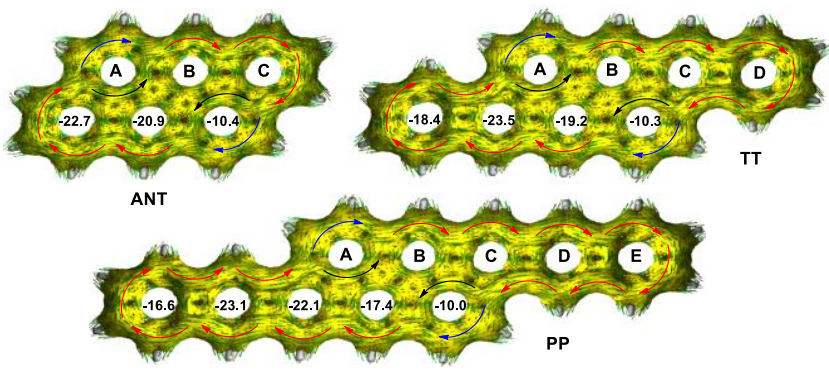

Figure 6. NICS(1.7) $)_{\pi z}$ calculations and acid plots of closed-shell forms of ANT, TT and PP

Accordingly, the closed-shell of $\mathbf{P P}$ can be considered as two tetracene fused at the face and bridged by two ethylenic spacer. Therefore, the open-shell character of $\mathbf{P P}$ occurs due to the concomitant opening of two tetracenes with the recovering of two extra aromatic sextets.

In the recent literature, there are two open shell systems namely peri-tetracene (PT) and its opened homologues tetrabenzo$[a, f, j, o]$ perylene (TBP) that involve the opening of two tetracenes (Figure 7). ${ }^{12}$ However, in these cases, the opening of the two tetracenes leads to the gain of three aromatic sextets instead of two indicating that the change of aromaticity between the closedand the open-shell for them is higher than for PP. In contrast, for the isomer of TBP namely dinaphto[a,j]perylene (DNP), the change of aromaticity between the closed- and the open-shell is lower than for PP since the biradical form has only one extra aromatic sextet (Figure 7). ${ }^{29}$ Consequently, DNP is a closed-shell system in the ground state according to DFT calculation even though DNP has a biradical character $y_{0}$ of $57 \%$ very closed to that of TIPS-HEX $(58 \%)$ (see Table 1). The difference between DNP and TIPS-HEX is the absorption behavior. DNP has a $\lambda_{\max }$ at $719 \mathrm{~nm}$ while TIPS-HEX absorbs at $740 \mathrm{~nm}$. Accordingly, it seems that for benzenoid PAHs functionalized with TIPSacetylene, the absorption cut-off should be around $740 \mathrm{~nm}$ to get a singlet biradical in the ground state.

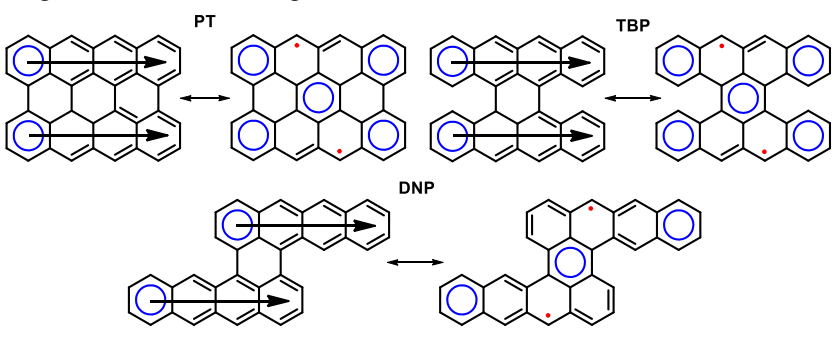

Figure 7. Resonance forms of PT, TBP and DNP.
It is noteworthy to know that for rylene ribbons, the concomitant opening of six naphthalenes is necessary to get an open-shell character while for anthenes, the open-shell character occurs with the opening of three anthracenes with the formation of three extra aromatic sextets. $^{13,11 a}$

X-ray Crystallographic Analysis: Single crystals of TT were obtained by slow evaporation from a chloroform solution. The crystal has a triclinic symmetry with $P-1$ space group. The molecule is not perfectly planar but slightly wavy due to the fact that at the bay region, the torsion angle between carbons $4,4 \mathrm{a}, 4 \mathrm{~b}$ and 5 is about $-9.36^{\circ}$ (Figure 8). Consequently, the experimental bond lengths are not strictly comparable to that of the calculated ones. Nevertheless, the bond lengths at the zigzag edge show bond length alternation. Even though the bond lengths of bonds a $(1.362 \AA)$ and $\mathbf{h}(1.363 \AA \AA)$ are nearly identical in contrast to the calculated ones $(1.356 \AA$ for $\mathbf{a}$ and $1.367 \AA$ for $\mathbf{h})$, the bond $\mathbf{b}$ is much longer (1.446 $\AA$ ) suggesting that the bonds $\mathbf{a}$ and $\mathbf{b}$ belong to a ring where the $\pi$-electrons are not delocalized but rather fixed. Moreover, even though the bonds lengths of bonds e (1.419 $\AA)$ and $\mathbf{f}(1.417 \AA)$ are longer than that of the calculated ones (1.397 $\AA$ for $\mathbf{e}$ and $1.399 \AA$ for $\mathbf{f})$, they are also nearly identical.

Amazingly, like TIPS-PEN, TT adopts a 2-D "bricklayer" arrangement even if the TIPS groups are not in the middle of the $\pi$ skeleton (Figure 8). ${ }^{3 a}$ The phenyl groups help at the arrangement of the molecules as they are in the middle of two TIPS of adjacent molecules. Due to the inversion center located at the middle of the stacked dimer, there are two alternating intermolecular center-tocenter distances of 7.63 and $9.67 \AA$ \&́ between adjacent molecules. The corresponding interplanar distances are 3.53 and $3.43 \AA$, respectively.

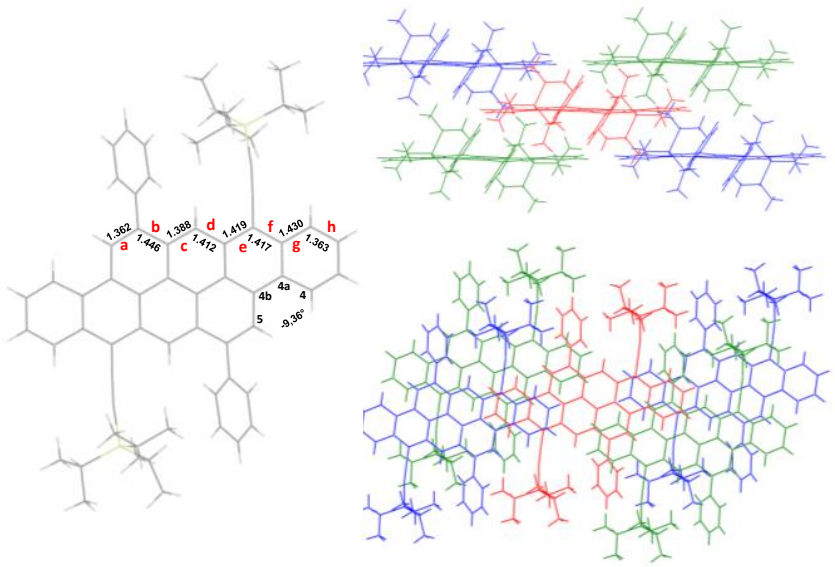

Figure 8. Experimental selected bond lengths and molecular packing of TT.

OFET Devices: Thanks to the stability of TT and PP, OFETs in solution-processed thin films were fabricated (see Supporting Information for details). Although organic semiconductors are intrinsically ambipolar and should be able to transport both holes and electrons, however, most PAHs including pentacene, only show unipolar p-type transport behavior in the standard device configuration using gold as the source and drain electrodes. ${ }^{30}$ In contrast, the small energy gap and the amphoteric redox character of TT and PP allow both carrier injection and an ambipolar charge transport in bottom-gate/top-contact (BG/TC) devices. A BG/TC device with the PP layer formed by the solution-shearing method showed balanced hole $\left(0.07 \mathrm{~cm}^{2} \mathrm{~V}^{-1} \mathrm{~s}^{-1}\right)$ and electron $\left(0.02 \mathrm{~cm}^{2} \mathrm{~V}^{-1} \mathrm{~s}^{-1}\right)$ mobilities (Figure 9), which are more than oneorder of magnitude higher than those previously reported for most biradical PAHs. ${ }^{8 \mathrm{e}, 10 \mathrm{e}, 10 \mathrm{~h}}$ Since the mobilities of small molecules are strongly related to the crystallinity of the films, which depends on the preparation method such as spin-coating, drop-casting, dipcoating or solution-shearing, we observed a better hole mobility 
for the drop-casted PP devices $\left(\mu_{\mathrm{h}}=0.21 \mathrm{~cm}^{2} \mathrm{~V}^{-1} \mathrm{~s}^{-1}\right.$ and $\mu_{\mathrm{e}}=$ $0.01 \mathrm{~cm}^{2} \mathrm{~V}^{-1} \mathrm{~s}^{-1}$ ) owing to the larger crystalline domains (See Supporting Information). The corresponding TT devices also showed ambipolar transport with slightly lower mobilities $\left(\mu_{\mathrm{h}}=\right.$ $0.14 \mathrm{~cm}^{2} \mathrm{~V}^{-1} \mathrm{~s}^{-1}$ and $\mu_{\mathrm{e}}=0.006 \mathrm{~cm}^{2} \mathrm{~V}^{-1} \mathrm{~s}^{-1}$ ). Further optimization resulted in better hole mobilities up to $1.4 \mathrm{~cm}^{2} \mathrm{~V}^{-1} \mathrm{~S}^{-1}$ and 0.77 $\mathrm{cm}^{2} \mathrm{~V}^{-1} \mathrm{~S}^{-1}$ for PP and TT, respectively, in TG/BC devices with CYTOP, which has a low dielectric constant and low interface trap sites. The increase of the hole mobilities in the large crystalline films makes observing the relatively low electron transport difficult. Since a single crystal of PP could not be obtained, the potential of PP has not been completely elucidated. However, the mobility of PP is much higher than that of polycrystalline TIPSPEN and many other PAHs fabricated by standard solution processes. These results proved that low band gap materials based on acenoacenes with closed- and open-shell structures are excellent organic semiconductors.
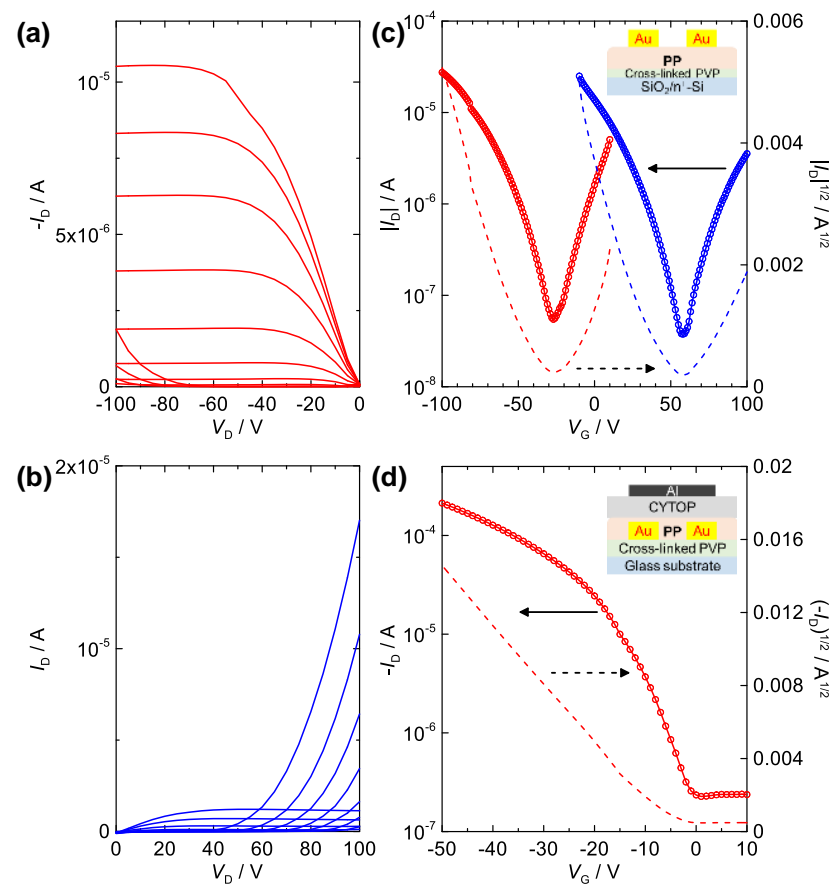

Figure 9. OFET devices of PP. (a) and (b) Output and (c) Transfer characteristics of a BG/TC device with a solution-sheared PP layer; (d) Transfer characteristics of a TG/BC device with a dropcasted PP layer.

\section{CONCLUSION}

We have reported the efficient synthesis of two peri-fused materials TT and PP. Suitably functionalized with TIPS-acetylene at the most reactive site and the presence of phenyl groups at the zigzag edge, TT and PP are low band gap materials of 1.79 and $1.42 \mathrm{eV}$, respectively, and exhibit remarkable high stability under ambient condition. Thanks to different experimental techniques and DFT calculations, we have shown that TT and PP have a closed-shell and open-shell configuration in the ground state, respectively. The open shell character of $\mathbf{P P}$ is related to the concomitant opening of two tetracenes with the recovering of two extra aromatic sextets and a small HOMO-LUMO energy gap (gap $<1.5 \mathrm{eV})$. Thanks to the high stability, thin films OFETs could be fabricated. In TG-BC configuration, PP shows remarkable hole mobility of $1.4 \mathrm{~cm}^{2} \mathrm{~V}^{-1} \mathrm{~s}^{-1}$ while TT exhibits a hole mobility of $0.77 \mathrm{~cm}^{2} \mathrm{~V}^{-1} \mathrm{~s}^{-1}$. In configuration BG-TC, ambipolar behaviors for both were obtained with hole and electron mobilities of 0.21 and $0.01 \mathrm{~cm}^{2} \mathrm{~V}^{-1} \mathrm{~s}^{-1}$ for PP and 0.14 and $0.006 \mathrm{~cm}^{2} \mathrm{~V}^{-1}$ $\mathrm{s}^{-1}$ for TT. Since PP is a singlet biradical in the ground state and exhibits high stability and high mobility, it could be one of the rare open shell materials suitable to be used in spintronics. ${ }^{7 a}, 31$ The synthesis of other pentacenopentacene isomers and longer homologues is underway in our laboratory.

\section{ASSOCIATED CONTENT}

\section{Supporting Information}

Synthesis, characterization, crystal data, device fabrication and theoretical calculations. The Supporting Information is available free of charge on the ACS Publications website.

\section{AUTHOR INFORMATION}

\section{Corresponding Author}

michel.frigoli@uvsq.fr ; mamada@opera.kyushu-u.ac.jp Notes

The authors declare no competing financial interests.

\section{ACKNOWLEDGMENT}

M.F. and A.Y. acknowledge financial support from the Agence Nationale de la Recherche ANR-16-CE07-0024 (GATE). T.J.-O. has been an International Research Fellow of the Japanese Society for the Promotion of Science (JSPS) for three months through the JSPS Summer Program and acknowledges CNRS for PhD grant. M.M. and C.A. acknowledge financial support from JST ERATO Grant No. JPMJER1305 and JSPS KAKENHI Grant No. JP19H02790. The authors thank Dr. W. J. Potscavage, Jr., for assistance in data processing.

\section{REFERENCES}

(1) (a) Bendikov, M.; Wudl, F.; Perepichka, D. F. Tetrathiafulvalenes, Oligoacenenes, and Their Buckminsterfullerene Derivatives: The Brick and Mortar of Organic Electronics. Chem. Rev. 2004, 104, 4891; (b) Anthony, J. E. Functionalized Acenes and Heteroacenes for Organic Electronics. Chem. Rev. 2006, 106, 5028. (c) Anthony, J. E. The larger acenes: versatile organic semiconductors. Angew. Chem. Int. Ed. 2008, 47, 452. (d) Qu, H.; Chi, C. Synthetic Chemistry of Acenes and Heteroacenes. Curr. Org. Chem. 2010, 14, 2070. (e) Sun, Z.; Ye, Q.; Chi, C.; Wu, J. Low band gap polycyclic hydrocarbons: from closed-shell near infrared dyes and semiconductors to open-shell radicals. Chem. Soc. Rev. 2012, 41, 7857. (f) Ye, Q.; Chi, C. Recent Highlights and Perspectives on Acene Based Molecules and Materials. Chem. Mater. 2014, 26, 4046.

(2) (a) Sirringhaus, H. 25th Anniversary Article: Organic Field Effect Transistors: The Path Beyond Amorphous Silicon. Adv. Mater. 2014, 26, 1319; (b) Roncali, J.; Leriche, P.; Blanchard, P. Molecular Materials for Organic Photovoltaics: Small is Beautiful. Adv. Mater. 2014, 26, 3821; (c) Wang, C.; Dong, H.; Hu, W. Liu, Y.; Zhu, D. Semiconducting $\pi$-Conjugated Systems in FieldEffect Transistors: A Material Odyssey of Organic Electronics. Chem. Rev. 2012, 112, 2208; (d) Mei, J.; Diao, Y.; Appleton, A. L.; Fang, L.; Bao, Z. Integrated Materials Design of Organic Semiconductors for Field-Effect Transistors. J. Am. Chem. Soc. 2013, 135, 6724. (e) Gao, X.; Zhao, Z. High mobility organic semiconductors for field-effect transistors. Sci. China Chem. 2015, 58, 947.

(3) (a) Anthony, J. E.; Brooks, J. S.; Eaton, D. L.; Parkin, S. R. Functionalized Pentacene: Improved Electronic Properties from Control of Solid-State Order. J. Am. Chem. Soc. 2001, 123, 9482; (b) Hamilton, R.; Smith, J.; Ogier, S.; Heeney, M.; Anthony, J. E.; McCulloch, I.; Veres, J.; Bradley, D. D. C.; Anthopoulos, T. D. High - Performance Polymer - Small Molecule Blend Organic Transistors. Adv. Mat. 2009, 21, 1166; (c) Kang, J.; Shin, N.; Jang, D. Y.; Prabhu, V. M.; Yoon, D. Y. Structure and Properties of Small Molecule-Polymer Blend Semiconductors for Organic Thin Film Transistors. J. Am. Chem. Soc. 2008, 130, 12273; (d) Maliakal, A.; Raghavachari, K.; Katz, H.; Chandross, E.; Siegrist, T. Photochemical Stability of Pentacene and a Substituted Pentacene in Solution and in Thin Film. Chem. Mater. 2004, 16, 4980. 
(4) (a) Brédas, J.-L.; Beljonne, D.; Coropceanu, V.; Cornil, J. Charge-Transfer and Energy-Transfer Processes in $\pi$-Conjugated Oligomers and Polymers: A Molecular Picture. Chem. Rev. 2004, 104, 4971; (b) Ortmann, F.; Radke, K. S.; Günther, A.; Kasemann, D.; Leo, K.; Cuniberti, G. Materials Meets Concepts in Molecule - Based Electronics. Adv. Funct. Mater. 2015, 25, 1933; (c) Watanabe, M.; Chang, Y. J.; Liu, S.-W.; Chao, T.-H.; Goto, K.; Islam, M. M.; Yuan, C.-H.; Tao, Y.-T.; Shinmyozu, T.; Chow, T. J. The synthesis, crystal structure and charge-transport properties of hexacene. Nat. Chem. 2012, 4, 574.

(5) (a) Payne, M. M; Parkin, S. R.; Anthony, J. E. Functionalized Higher Acenes: Hexacene and Heptacene. J. Am. Chem. Soc. 2005, 127, 8028; (b) Chun, D.; Cheng, Y.; Wudl, F. The most stable and fully characterized functionalized heptacene. Angew. Chem. Int. Ed. 2008, 47, 8380; (c) Qu, E.; Chi, C. A Stable Heptacene Derivative Substituted With Electron-Deficient Trifluoromethylphenyl and Triisopropylsilylethynyl Groups. Org. Lett. 2010, 12, 3360; (d) Tonshoff, C.; Bettinger, H. F. Beyond pentacenes: synthesis and properties of higher acenes. Top. Curr. Chem. 2014, 349, 1. (e) Thorley, K. J.; Anthony J. E. The Electronic Nature and Reactivity of the Larger Acenes. Isr. J. Chem. 2014, 54, 642 and references therein.

(6) (a) M. Bendikov, H. M. Duong, K. Starkey, K. N. Houk, E. A. Carter, Wudl, F. Oligoacenes: Theoretical Prediction of OpenShell Singlet Diradical Ground States. J. Am. Chem. Soc. 2004, 126, 7416; (b) Huang, R.; Phan, H.; Herng, T. S.; Hu, P.; Zeng, W.; Dong, S-Q.; Das, S.; Shen, Y.; Ding, J.; Casanova, D.; Wu, J. Higher Order $\pi$-Conjugated Polycyclic Hydrocarbons with OpenShell Singlet Ground State: Nonazethrene versus Nonacene. $J$. Am. Chem. Soc. 2016, 138, 10323.

(7) Recent Review on biradicaloid systems: (a) Gopalakrishna, T. Y.; Zeng, W.; Lu, X.; Wu, J. From open-shell singlet diradicaloids to polyradicaloids. Chem. Commun. 2018, 54, 2186; (b) Hu, X.; Wang, W.; Wang, D.; Zheng, Y. The electronic applications of stable diradicaloids: present and future. J. Mater. Chem. C 2018, 6,11232

(8) (a) Ohashi, K.; Kubo, T.; Masui, T.; Yamamoto, K.; Nakasuji, K.; Takui, T.; Kai, Y.; Murata, I. 4,8,12,16-Tetra-tert-butyl-sindaceno[1,2,3-cd:5,6,7-c'd ']diphenalene: A Four-Stage Amphoteric Redox System. J. Am. Chem. Soc. 1998, 120, 2018; (b) Kubo, T.; Sakamoto, M.; Akabane, M.; Fujiwara, Y.; Yamamoto, K.; Akita, M.; Inoue, K.; Takui, T.; Nakasuji, K. Four - Stage Amphoteric Redox Properties and Biradicaloid Character of Tetra tert - butyldicyclopenta[b;d]thieno[1,2,3 - $c d ; 5,6,7-c^{\prime} d^{\prime}$ Jdiphenalene. Angew. Chem., Int. Ed. 2004, 43, 6474; (c) Shimizu, A.; Kubo, T.; Uruichi, M.; Yakushi, K.; Nakano, M.; Shiomi, D.; Sato, K.; Takui, T.; Hirao, Y.; Matsumoto, K.; Kurata, H.; Morita, Y.; Nakasuji, K. Alternating Covalent Bonding Interactions in a One-Dimensional Chain of a Phenalenyl-Based Singlet Biradical Molecule Having Kekulé Structures. J. Am. Chem. Soc. 2010, 132, 14421; (d) Shimizu, A.; Hirao, Y.; Matsumoto, K.; Kurata, H.; Kubo, T.; Uruichi, M.; Yakushi, K. Aromaticity and $\pi$-bond covalency: prominent intermolecular covalent bonding interaction of a Kekulé hydrocarbon with very significant singlet biradical character. Chem. Commun. 2012, 48, 5629; (e) Koike, H.; Chikamatsu, M.; Azumi, R.; Tsutsumi , J. Y.; Ogawa , K.; Yamane, W.; Nishiuchi, T.; Kubo, T.; Hasegawa, T.; Kanai, K. Stable Delocalized Singlet Biradical Hydrocarbon for Organic Field Effect Transistors. Adv. Funct. Mater. 2016, 26, 277.

(9) (a) Sun, Z.; Huang K.-W.; Wu, J. Soluble and Stable Heptazethrenebis(dicarboximide) with a Singlet Open-Shell Ground State. J. Am. Chem. Soc. 2011, 133, 11896; (b) Li, Y.; Heng, W.K.; Lee, B. S.; Aratani, N. Zafra, J. L.; Bao, N.; Lee, R.; Sung, Y. M.; Sun, Z.; Huang, K.-W.; Webster,, R. D.; López Navarrete, J. T.; Kim, D.; Osuka; A.; Casado, J.; Ding, J.; Wu, J. Kinetically Blocked Stable Heptazethrene and Octazethrene: Closed-Shell or Open-Shell in the Ground State?. J. Am. Chem. Soc. 2012, 134, 14913; (c) Das, S.; Lee, S.; Son, M.; Zhu, X.; Zhang, W.; Zheng, B.; Hu, P.; Zeng, Z.; Sun, Z.; Zeng, W.; Li, R.; Huang, K.; Ding, J.; Kim, D.; Wu, J. para - Quinodimethane - Bridged Perylene Dimers and Pericondensed Quaterrylenes: The Effect of the Fusion Mode on the Ground States and Physical Properties. Chem. Eur. J. 2014, 20, 11410; (d) Yadav, P.; Das, S.; Phan, H.; Herng, T. S.; Ding, J.; Wu, J. Kinetically Blocked Stable 5,6:12,13Dibenzozethrene: A Laterally $\pi$-Extended Zethrene with Enhanced Diradical Character. Org. Lett. 2016, 18, 2886; (e) Zeng,
W.; Sun, Z.; Herng, T. S.; Gonçalves, T. P.; Gopalakrishna, T. Y.; Huang, K.-W.; Ding, J.; Wu, J. Super - heptazethrene. Angew. Chem. Int. Ed. 2016, 55, 8615; (f) Zeng, W.; Gopalakrishna, T. Y.; Phan, H.; Tanaka, T.; Herng, T. S.; Ding, J.; Osuka, A.; Wu, J. Superoctazethrene: An Open-Shell Graphene-like Molecule Possessing Large Diradical Character but Still with Reasonable Stability. J. Am. Chem. Soc. 2018, 140, 14054.

(10) (a) Shimizu, A.; Kishi, R.; Nakano, M.; Shiomi, D.; Sato, K.; Takui, T.; Hisaki, I.; Miyata, M.; Tobe, Y. Indeno[2,1-b]fluorene: a $20-\pi$-electron hydrocarbon with very low-energy light absorption. Angew. Chem. Int. Ed. 2013, 52, 6076; (b) Rudebusch, G. E.; Fix, A. G.; Henthorn, H. A.; Vonnegut, C. L.; Zakharov, L. N.; Haley, M. M. Quinoidal diindenothienoacenes: synthesis and properties of new functional organic materials. Chem. Sci. 2014, 5 , 3627; (c) Miyoshi, H.; Nobusue, S.; Shimizu, A.; Hisaki, I.; Miyatab, M.; Tobe, Y. Benz $[c]$ indeno[2,1-a]fluorene: a 2,3naphthoquinodimethane incorporated into an indenofluorene frame. Chem. Sci. 2014, 5, 163; (d) Shi, X.; Quintero, E.; Lee, S.; Jing, L.; Herng, T. S.; Zheng, B.; Huang, K-W.; López Navarrete, J. T.; Ding, J.; Kim, D.; Casado. J.; Chi, C. Antiaromatic bisindeno- $[n]$ thienoacenes with small singlet biradical characters: syntheses, structures and chain length dependent physical properties. Chem. Sci. 2014, 5, 4490; (e). Rudebusch, G. E.; Zafra, J. L.; Jorner, K.; Fukuda, K.; Marshall, J. L.; Arrechea-Marcos, I.; Espejo, G. L.; Ponce Ortiz, R.; Gómez-García, C. J.; Zakharov, L. N.; Nakano, M.; Ottosson, H.; Casado, J.; Haley, M. M. Diindeno-fusion of an anthracene as a design strategy for stable organic biradicals. Nat. Chem. 2016, 8, 753; (f) Maekawa, T.; Ueno, H.; Segawa, Y.; Haley, M. M.; Itami, K. Synthesis of open-shell ladder $\pi$-systems by catalytic $\mathrm{C}-\mathrm{H}$ annulation of diarylacetylenes. Chem. Sci. 2016, 7, 650; (g) Ma, J.; Liu, J.; Baumgarten, M.; Fu, Y.; Tan, Y.-Z.; Schellhammer, K. S.; Ortmann, F.; Cuniberti, G.; Komber, H.; Berger, R.; Müllen, K.; Feng, X. A Stable Saddle Shaped Polycyclic Hydrocarbon with an Open - Shell Singlet Ground State. Angew. Chem., Int. Ed. 2017, 56 , 3280; (h) Hsieh, Y-C.; Wu, C-F.; Chen, Y-T.; Fang, C-T.; Wang, C-S.; Li, C-H.; Chen, L-Y.; Cheng, M-J.; Chueh, C-C.; Chou,P-T.; Wu, Y-T. 5,14-Diaryldiindeno[2,1-f:1' ,2' $-j$ ]picene: A New Stable [7]Helicene with a Partial Biradical Character. J. Am. Chem. Soc. 2018, 140, 14357; (i) Dressler, J. J.; Teraoka, M.; Espejo, G. L.; Kishi, R.; Takamuku, S.; Gómez-García, C. J.; Zakharov, L. N.; Nakano, M.; Casado, J.; Haley, M. M. Thiophene and its sulfur inhibit indenoindenodibenzothiophene diradicals from low-energy lying thermal triplets. Nat. Chem. 2018, 10, 1134; (j)_Shimizu, A.; Nobusoe, S.; Miyoshi, H.; Tobe, Y. Indenofluorene congeners: Biradicaloids and beyond. Pure Appl. Chem. 2014, 86, 517.

(11) Konishi, A.; Hirao, Y.; Nakano, M.; Shimizu, A.; Botek, E.; Champagne, B. t.; Shiomi, D.; Sato, K.; Takui, T.; Matsumoto, K.; Kurata, H.; Kubo, T. Synthesis and Characterization of Teranthene: A Singlet Biradical Polycyclic Aromatic Hydrocarbon Having Kekulé Structures. J. Am. Chem. Soc. 2010, 132, 11021; (b) Konishi, A.; Hirao, Y.; Matsumoto, K.; Kurata, H.; Kishi, R.; Shigeta, Y.; Nakano, M.; Tokunaga, K.; Kamada, K.; Kubo, T. Synthesis and Characterization of Quarteranthene: Elucidating the Characteristics of the Edge State of Graphene Nanoribbons at the Molecular Level. J. Am. Chem. Soc. 2013, 135, 1430.

(12) (a) Liu, J.; Ravat, P.; Wagner, M.; Baumgarten, M.; Feng, X.; Müllen, K. Tetrabenzo[ $[a, f, j, o]$ perylene: A Polycyclic Aromatic Hydrocarbon With An Open - Shell Singlet Biradical Ground State. Angew. Chem., Int. Ed. 2015, 54, 12442; (b) Ajayakumar, M. R.; Fu, Y.; Ma, J.; Hennersdorf, F.; Komber, H.; Weigand, J. J.; Alfonsov, A.; Popov, A. A.; Berger, R.; Liu, J.; Müllen, K.; Feng, X. Toward Full Zigzag-Edged Nanographenes: periTetracene and Its Corresponding Circumanthracene. J. Am. Chem. Soc. 2018, 140, 6240; (c) Ni, Y.; Gopalakrishna, T. Y.; Phan, H.; Herng, T. S.; Wu, S.; Han, Y.; Ding, J.; Wu, J. A Peri-tetracene Diradicaloid: Synthesis and Properties. Angew. Chem. Int. Ed. 2018, 57, 9697.

(13) Zeng, W.; Phan, H.; Herng, T. S.; Gopalakrishna, T. Y.; Aratani, N.; Zeng, Z.; Yamada, H.; Ding, J.; Wu, J. Rylene Ribbons with Unusual Diradical Character. Chem 2017, 2, 81.

(14) (a) Zhang, L.; Fonari, A.; Liu, Y.; Hoyt, A.-L. M.; Lee, H.; Granger, D.; Parkin, S.; Russell, T. P.; Anthony, J. E.; Brédas, J.L.; Coropceanu, V.; Briseno, A. L. Bistetracene: An Air-Stable, High-Mobility Organic Semiconductor with Extended Conjugation. J. Am. Chem. Soc. 2014, 136, 9248; (b) Sbargoud, K.; 
Mamada, M.; Jousselin-Oba, T.; Takeda, Y.; Tokito, S.; Yassar, A.; Marrot, J.; Frigoli, M. Low Bandgap Bistetracene - Based Organic Semiconductors Exhibiting Air Stability, High Aromaticity and Mobility. Chem. Eur. J. 2017, 23, 5076; (c) Reus, C.; Lechner, M. P.; Schulze, M.; Lungerich, D.; Diner, C.; Gruber, M.; Stryker, J. M.; Hampel, F.; Jux, N.; Tykwinski, R. R. Unexpected Michael Additions on the Way to 2.3,8.9 Dibenzanthanthrenes with Interesting Structural Properties. Chem. Eur. J. 2016, 22, 9097; (d) Wang, Z.; Li, R.; Chen, Y.; Tan, Y.-Z.; Tu, Z.; Gao, X. J.; Dong, H.; Yi, Y.; Zhang, Y.; Hu, W.; Mullen, K.; Chen, L. A novel angularly fused bistetracene: facile synthesis, crystal packing and single-crystal field effect transistors. J. Mater. Chem. C, 2017, 5, 1308.

(15) Thomas, S.; Ly, J.; Zhang, L.; Briseno, A. L.; Bredas, J.-L. Improving the Stability of Organic Semiconductors: Distortion Energy versus Aromaticity in Substituted Bistetracene. Chem. Mater. 2016, 28, 8504 .

(16) Broman, S. r. L. k.; Andersen, C. L.; Jousselin-Oba, T.; Mans $\tilde{s}_{s}$, M.; Hammerich, O.; Frigoli, M.; Nielsen, M. B. Tetraceno[2,1,12,11-opqra]tetracene-extended tetrathiafulvalene redox-controlled generation of a large PAH core. Org. Biomol. Chem. 2017, 15, 807.

(17) Zhang, L.; Walker, B.; Liu, F.; Colella, N. S.; Mannsfeld, S. C. B.; Watkins, J. J.; Nguyen, T.-Q.; Briseno, A. L. Triisopropylsilylethynyl-functionalized dibenzo[def,mno]chrysene: a solutionprocessed small molecule for bulk heterojunction solar cells. $J$. Mater. Chem. 2012, 22, 4266.

(18) Lungerich, D.; Papaianina, O.; Feofanov, M.; Liu, J.; Devarajulu, M.; Troyanov, S. I.; Maier, S.; Amsharov, K. Dehydrative $\pi$ extension to nanographenes with zig-zag edges. Nat. Commun. 2018, 9, 4756.

(19) Jousselin-Oba, T.; Sbargoud, K.; Vaccaro, G.; Meinardi, F.; Yassar, A.; Frigoli, M. Novel Fluorophores based on Regioselective Intramolecular Friedel-Crafts Acylation of the Pyrene Ring Using Triflic Acid. Chem. Eur. J. 2017, 23, 16184.

(20) (a) Di Motta, S.; Negri, F.; Fazzi, D.; Castiglioni, C.; Canesi, E. V. Biradicaloid and Polyenic Character of Quinoidal Oligothiophenes Revealed by the Presence of a Low-Lying Double-Exciton State. J. Phys. Chem. Lett. 2010, 1, 3334; (b) Canola, S.; Casado, J.; Negri, F. The double exciton state of conjugated chromophores with strong diradical character: insights from TDDFT calculations. Phys. Chem. Chem. Phys. 2018, 20, 24227.
(21) Yamakado, T.; Takahashi, S.; Watanabe, K.; Matsumoto, Y.; Osuka, A.; Saito, S. Conformational Planarization versus Singlet Fission: Distinct Excited - State Dynamics of Cyclooctatetraene - Fused Acene Dimers. Angew. Chem. Int. Ed. 2018, 57, 5438.

(22) Itoh, T. Fluorescence and Phosphorescence from Higher Excited States of Organic Molecules. Chem. Rev. 2012, 112, 4541.

(23) Bleaney, B.; Bowers, K. D. Anomalous paramagnetism of copper acetate. Proc, R. Soc. London Ser. A 1952, 214, 451.

(24) Chilton, N. F.; Anderson, R. P.; Turner, L. D.; Soncini, A.; Murray, K. S. PHI: a powerful new program for the analysis of anisotropic monomeric and exchange-coupled polynuclear d- and fblock complexes. J. Comput. Chem. 2013, 34, 1164.

(25) (a) A. Rahalkar, A. Stanger, Aroma: http://chemistry.technion.ac.il/members/amnon-stanger/; (b) Stanger, A. Nucleus-Independent Chemical Shifts (NICS): Distance Dependence and Revised Criteria for Aromaticity and Antiaromaticity. J. Org. Chem. 2006, 71, 883; (c) Stanger, A. OTTaining Relative Induced Ring Currents Quantitatively from NICS. J. Org. Chem. 2010, 75, 2281; (d) Gershoni-Poranne, R.; Stanger, A. The NICS - XY - Scan: Identification of Local and Global Ring Currents in Multi - Ring Systems. Chem. Eur. J. 2014, 20, 5673 .

(26) (a) Herges, R.; Geuenich, D. Delocalization of Electrons in Molecules, J. Phys. Chem. A 2001, 105, 3214; (b) Geuenich, D.; Hess, K.; Kohler, F.; Herges, R. Anisotropy of the Induced Current Density (ACID), a General Method To Quantify and Visualize Electronic Delocalization. Chem. Rev. 2005, 105, 3758.

(27) Doehnert, D. Koutecky, J. Occupation numbers of natural orbitals as a criterion for biradical character. Different kinds of biradicals. J. Am. Chem. Soc. 1980, 102, 1789.

(28) The Aromatic Sextet, E. Clar, John Wiley \& Sons, London, 1972, pp 81-82; Polycyclic Hydrocarbons, I, E. Clar, Academic Press, New York, 1964, I, p. 46

(29) Liu, X.; Chen, M.; Xiao, C.; Xue, N.; Zhang, L. Soluble Twisted Diarenoperylenes: Synthesis, Characterization, and Device Performance. Org. Lett. 2018, 20, 4512.

(30) Takeshi, Y.; Takeshi, G.; Katsuhiko, F.; Tetsuo, T. Ambipolar pentacene field-effect transistors with calcium source-drain electrodes. Appl. Phys. Lett. 2004, 85, 2098.

(31) Dediu, V. A.; Hueso, L. E.; Bergenti, I.; Taliani, C. Spin routes in organic semiconductors. Nat. Mater. 2009, 8,850 . 

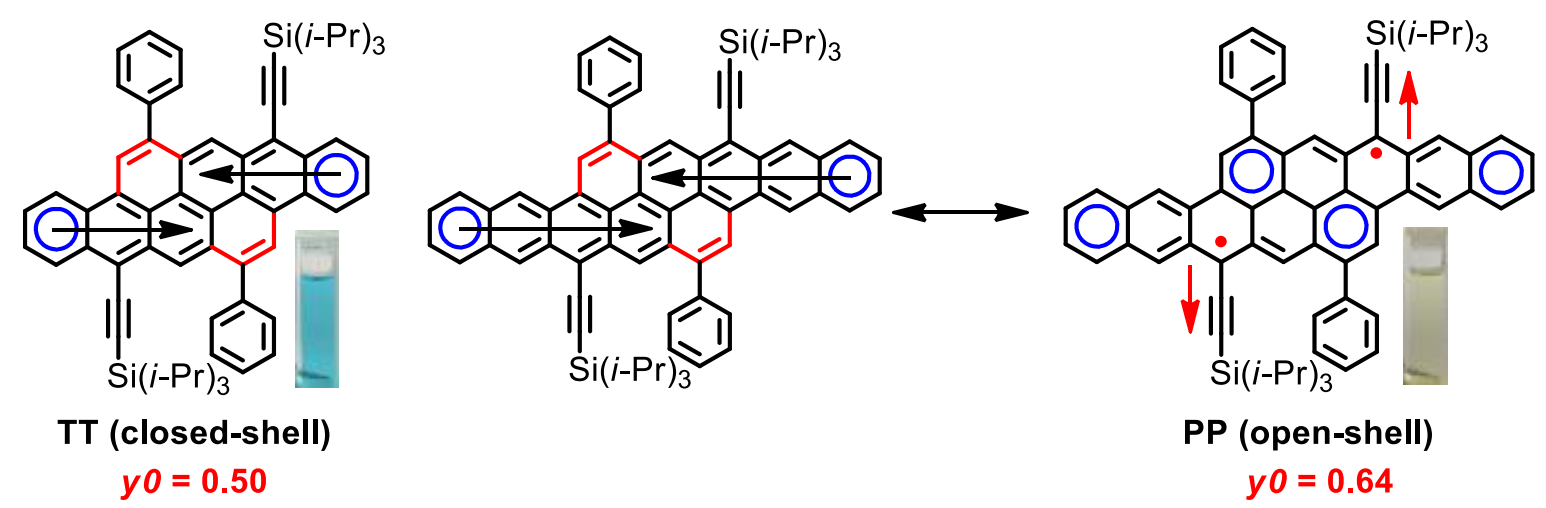